\title{
Improving Metropolitan Transportation Efficiency With FAST Miles
}

\author{
Patrick DeCorla-Souza, Federal Highway Administration
}

\begin{abstract}
In America's large and severely congested metropolitan areas, carpools and express bus service could attract many more riders if they could operate between residential areas and job centers on free-flowing highways that provide premium service opportunities. FAST Miles attempts to eliminate recurring congestion on limited-access highway systems using a potentially more publicly acceptable form of road pricing, along with an integrated multimodal strategy to encourage shifts of solo-driving commuters to alternative modes. FAST Miles allocates to motorists a limited number of free miles for use in peak periods on limited-access highways. Every motorist would get a share of free peak-period use of FAST highway facilities "already paid for" through his or her taxes through free FAST Miles credits. Total outstanding credits would be limited to ensure that the metropolitan highway system does not get congested and that express bus services operate faster, providing better levels of service at a lower cost.

The concept would include new express bus and carpooling services, improved passenger collection and distribution services at bus transfer stations, free transit trial periods, web-based multimodal trip-planning programs, and individualized marketing of alternative modes at employment centers and in residential areas. Preliminary sketch analysis suggests that FAST Miles could be self-financing. It also would introduce new possibilities for public-private partnerships.
\end{abstract}




\section{Introduction}

Several metropolitan planning organizations have proposed networks of premium-service bus/high-occupancy vehicle (HOV) lanes or high-occupancy toll (HOT) lanes to create free-flowing traffic conditions for buses and HOVs. However, funds available to invest in complete networks of such facilities are inadequate due to high costs for highway facility expansion and special direct access ramps that are needed to provide safe access for buses. For example, a feasibility study for a network of HOT lanes in the Twin Cities of Minnesota suggests that tolls could pay for only 15 to 55 percent of the cost of building the lanes (Cambridge Systematics, Inc. and URS Corporation 2005). In some cases, limited rightsof-way and environmental and community impacts preclude highway expansion altogether, leaving some segments where buses would need to run in mixed traffic on congested highways.

This article presents a new concept called FAST Miles that seeks to create a complete premium-service express bus and HOV network without an immediate need for highway expansion, while at the same time providing new incentives for HOV and transit use through improved passenger collection and distribution services at residential and employment ends of the commute trip. The word FAST in FAST Miles is not used as an acronym, but simply represents the fast highway service provided by this concept.

\section{The FAST Miles Concept}

One cellular phone plan offered in the United States (i.e., Verizon) allows an unlimited number of free calls during off-peak periods and weekends, but limits free minutes on weekdays during the peak daytime period. Customers pay per minute charges for calls above the free limit during peak periods. The phone company is able to eliminate daytime congestion. This reduces the need to add expensive new capacity to serve discretionary calls during peak periods and encourages people to make these calls during off-peak times.

This phone service charging concept may be transferable to public services subject to peak demands, such as transportation. FAST Miles is such a concept. It allocates to motorists a limited number of free miles for use in peak periods on freewaytype limited-access highways called FAST highways. Every motorist would get a share of peak-period use of FAST highway facilities "already paid for" through his or her taxes through free FAST Miles credits. Total outstanding credits are limited 
to ensure that the metropolitan highway system does not get congested and that express bus services operate faster, providing better levels of service at lower cost.

All metropolitan-area motorists would be provided with an electronic transponder-a device that would capture miles driven on limited-access highways during the morning and afternoon peak periods. ATM-like machines now dispense transponders in sticker form for as little as $\$ 5$ each in Puerto Rico. Out-of-towners could obtain transponders from such machines at visitor centers or through the mail. With a nationally coordinated FAST Miles program, "sticker" transponders could be made available to all motorists nationwide.

Each licensed motorist would get a personal FAST Miles account that would be replenished daily with free credits for a limited number of free peak-period highway miles for that day. Additional miles could be purchased at rates that would depend on congestion levels. Rates per mile would be set high enough to dissuade discretionary trip-makers from peak-period use. This would help assure that demand does not exceed supply of congestion-free road space available and would help prevent the breakdown of the free flow of traffic. The extent of the highway system on which peak-period highway mileage charges would apply would be determined based on the extent of existing congestion on the system.

Mileage charges would apply only to limited-access FAST highways and only during peak periods. Charges are generally not practical on surface arterials. To charge for use of surface arterials, transponder readers would generally be needed on every block to prevent motorists from attempting to evade charges by diverting to parallel streets at charging points. This would increase implementation costs significantly. Therefore, with FAST Miles, tolls would not be charged on surface streets at any time of the day.

Congestion levels vary both by highway segment location and by the specific time of travel within the peak period. Therefore, free miles would be charged to motorists' accounts at a discounted rate during those times and on those segments that have less heavy demand. Conversely, free mile "surcharges" would be applied to more heavily used segments and at more heavily used times (i.e., motorists would need to use their free miles at a higher rate than actual miles driven).

Those participating in carpools and vanpools could link their FAST Miles accounts. This might be accomplished, for example, by registering with the metropolitan ridesharing agency. This would allow those who currently drive solo in single- 
occupant vehicles (SOVs) and have long commute trips to avail themselves of additional free miles by sharing the ride. Transit operators could attract longdistance suburban commuters by providing a fare credit equal to the value of the commuter's free FAST Miles if the commuter links his or her FAST Miles and transit fare card accounts.

If desired, trading systems could be set up, so that motorists who do not use their free miles would be able to cash in on their unused miles (DeCorla-Souza 1994). However, this would reduce the number of free miles that could be offered to those who currently use the highways in peak periods, potentially increasing opposition from them. Also, it may be negatively perceived as providing "windfall profits" to those who currently do not use the highway system during peak periods.

Long-distance commuters who value their time highly may still choose to drive alone and pay for extra miles. Surplus revenue from extra-mile payments could be dedicated to uses that would benefit these commuters. For example, relatively low-cost improvements such as signal coordination may be implemented on alternate nonpriced surface streets that long-distance commuters might choose to use to avoid extra highway mileage charges. Transit operators may be provided with public subsidies equal to the value of FAST Miles credits turned in to them by those patrons who commute long distances on transit. FAST highways may be expanded or transit capacity in the corridor enhanced, whichever is more costeffective, to accommodate their higher rates of peak use. Park-and-ride facilities, pedestrian and bicycle access (including bike rental facilities at bus stations), and shared-ride taxi services may be provided in suburban residential communities and at employment centers to facilitate the use of carpools or transit.

Providing incentives for use of non-SOV modes reduces vehicular travel demand. Those long-distance commuters who choose to drive alone and pay for the privilege will benefit from reduced vehicular travel demand resulting from mode shifts, because rates they would have to pay for extra miles would be lower. Rates would be lower because prices needed to eliminate recurring congestion would be lower when vehicular travel demand is reduced.

The FAST Miles concept would in effect produce what has been termed a "Fast And Intertwined Regular" (FAIR) highway network-a metropolitan highway system with two classes of service: a FAST network of free-flowing limited-access highways allowing for efficient and effective operation of express bus services; and a regular network of surface arterials (DeCorla-Souza 2005). 


\section{Can Demand for Highway Use Be Reduced?}

Traffic volume-speed relationships suggest that reducing existing peak-period highway traffic levels by relatively small amounts, as little as 10 percent, can eliminate recurring highway congestion (Transportation Research Board 2000). Drivers in the Washington, D.C. metropolitan area notice this phenomenon in August when peak-hour traffic is reduced by only small amounts due to some commuters being on vacation. Californians observe it on days when only state government employees are off work due to a state holiday (Wachs 2003). In such situations, there is not sufficient time for "equilibrium" with regard to traffic congestion to be restored (i.e., people who previously changed their mode, route, or time of travel choice due to congestion do not immediately get back on the highways during the peak periods to take advantage of the reduced congestion).

FAST Miles, when combined with improved modal alternatives, would provide a new incentive for a relatively small number of solo drivers with long commutes to reduce their highway use during peak periods by seeking alternative commuting arrangements. Solo drivers whose highway trip lengths exceed their free FAST Miles allocation would be more likely to consider carpooling, taking transit, telecommuting more often, driving during off-peak periods or on non-FAST facilities, or-in the longer term-moving closer to their jobs. Charges for extra miles would reduce the incentive for others, such as those long-distance commuters who previously changed their travel behavior due to congestion, to get back on the highway in peak periods to take advantage of free-flowing traffic conditions.

According to a recent Washington Post-ABC News poll (Langer 2005; Washington Post 2005), one third of those who drive to work alone in the Washington D.C. metropolitan area say they could take transit but do not. If they were to choose transit, SOV commuter traffic might be reduced by 33 percent. Nationwide, while just 8 percent of commuters currently carpool, 20 percent of solo drivers say that they would be interested in it-enough to take at least 10 percent of SOV commute vehicles off the road, assuming that each solo driver would share the ride with one other solo driver; or as much as 20 percent if it is assumed that all those solo drivers would join an existing carpool.

Achieving the relatively small reduction in peak-period traffic required to achieve free-flowing traffic conditions might not be as difficult as conventional wisdom might suggest. The U.S. Department of Transportation's 2001 National Household Travel Survey (U.S. Department of Transportation 2004) suggests that, in metropolitan areas with more than half a million people, one-way commute trips 
more than 20 miles long make up only 13 to 17 percent of all commute trips, but account for 37 to 45 percent of commute miles traveled. If heavy highway usage by these longer trips can be reduced by one third by encouraging use of transit and carpooling, this would amount to only about 4 to 6 percent of all commute trips. But such a relatively small reduction could decrease commute vehicle miles traveled by 12 to 15 percent, possibly sufficient to restore free-flowing traffic conditions in peak periods.

The National Household Travel Survey also found that only 50 percent of trips are work-commute related in the morning peak period, while less than 30 percent are work-commute related in the afternoon peak. This suggests that many peakperiod trips may be discretionary in nature. These trip-makers may be more easily dissuaded from using highways during peak periods and may have more flexibility to shift their time of travel to off-peak periods. In fact, on a set of two tolled bridges in Lee County, Florida, when a discount of just 25 cents was offered for travel before and after the heaviest travel periods, more than 70 percent of motorists eligible for the discounts chose to shift their time of travel to the discount periods at least once a week (Berg et al. 1999).

\section{Costs to Implement FAST Miles}

\section{Costs for Toll Collection, Credit Distribution, and Traffic Management}

Table 1 presents estimates of typical costs to implement FAST Miles in a large metropolitan area-Washington, D.C. This metropolitan region has about 4 million people. About two thirds of residents are licensed drivers and each driver generates about 3.8 vehicle trips each weekday (U.S. Department of Transportation 1999). Thus, a total of about 10 million vehicle trips are generated each weekday. Almost 40 percent of travel occurs in peak periods (U.S. Department of Transportation 1999). This means that about 4 million vehicle trips are carried on the regional highway system in peak periods. At an average trip length of 11.84 miles (U.S. Department of Transportation 1999), about 48 million vehicle miles of travel occur on the highway system during the morning and afternoon peak periods.

In Washington, D.C., about 42 percent of travel is carried on limited-access highways (U.S. Department of Transportation 2003). It is estimated that about 20 million vehicle miles are carried on the limited-access highway system in peak periods. The average distance traveled by the 4 million peak-period trips on the limitedaccess highway system may thus be calculated as almost 5 miles. (This average 


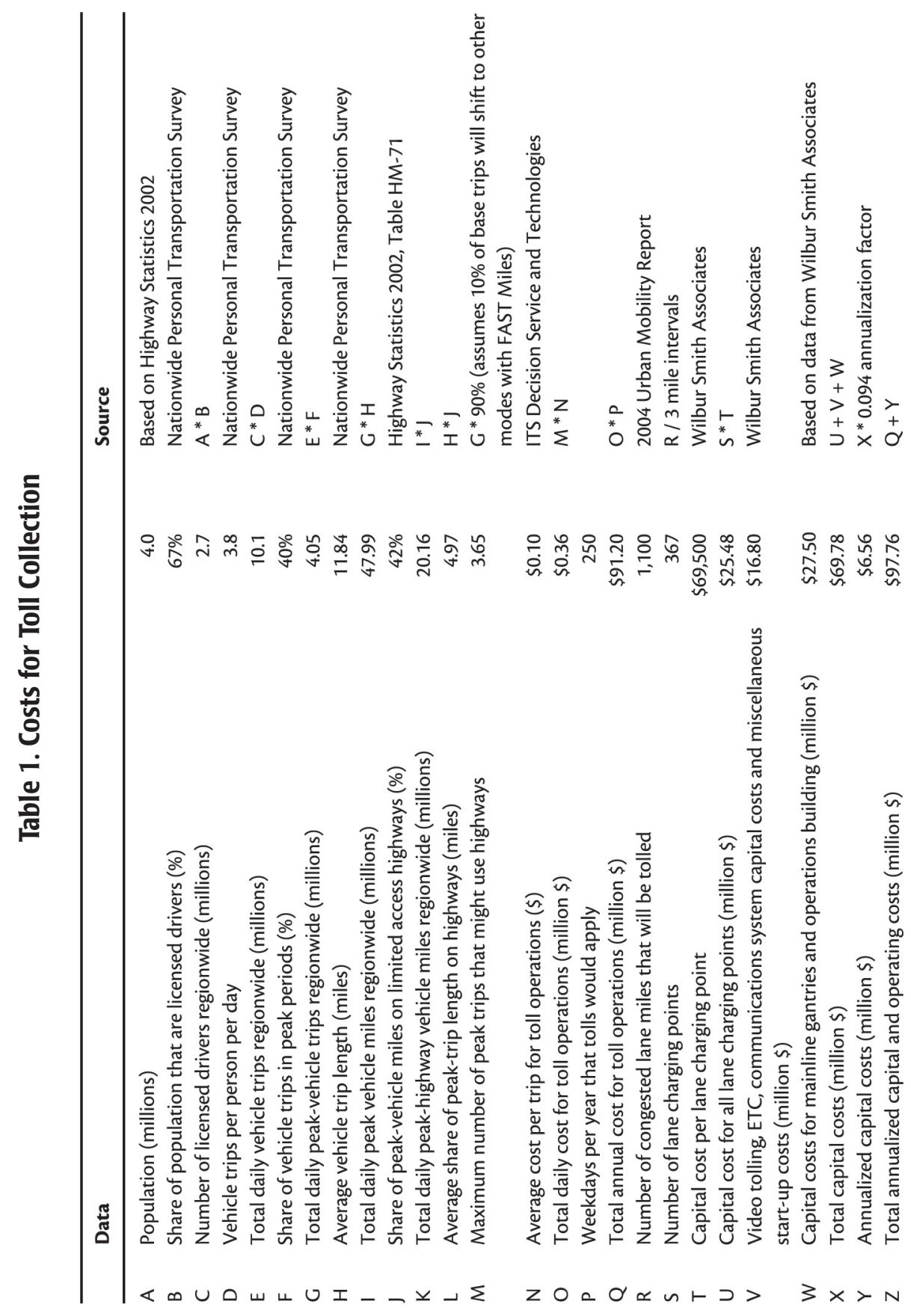


includes some trips that may not use the limited-access highway system at all.) Conservatively assuming that all of the 4 million trips currently use the limitedaccess highway system for a part of their trip lengths, and that 10 percent of these trips would shift to alternative modes with FAST Miles, a maximum of about 3.65 million trips would use the highway system daily during peak periods.

Costs for toll collection are estimated at 5 to 10 cents per trip by ITS Decision, Service and Technologies (2005). Toll collection costs will decrease with large-scale implementation. However, administration of a FAST Miles system may be more complex and therefore more costly than a typical toll collection system, due to dispensing of daily credits, flexible use of credits on transit, etc. Therefore, costs for the FAST Miles system are estimated at the high end, at about 10 cents per trip, including costs for traffic monitoring and management. Therefore, a FAST Miles system in Washington, D.C., with 3.65 million peak-period highway trips would cost about $\$ 365,000$ per day to operate, or about $\$ 91$ million over the 250 weekdays each year that the FAST Miles system would be in operation-not an insignificant cost.

Table 1 also provides estimates for toll collection capital costs based on cost data for open road tolling provided by Wilbur Smith \& Associates. It is assumed that the FAST highway network will employ open road tolling, with toll charging points located at approximately 3-mile intervals along 1,100 lane miles of congested FAST highway segments in the Washington, D.C. metropolitan area (Schrank and Lomax 2005), resulting in the need for 367 lane-charging points.

Capital costs per lane-charging point are estimated at $\$ 46,000$ for Electronic Toll Collection (ETC) costs and $\$ 23,500$ for Video Enforcement System (VES) costs, or a total of $\$ 69,500$ per lane-charging point, resulting in total costs of $\$ 25.5$ million for the whole FAST highway network. Video tolling hardware and software, ETC equipment, system software, communications system, other equipment, and miscellaneous installation, project management and training costs are estimated at a total of $\$ 16.8$ million. Mainline gantry costs are estimated at $\$ 25$ million and operations building costs at $\$ 2.5$ million.

Total capital costs are estimated at $\$ 70$ million. Annualized at a 7 percent discount rate and 20-year payback period, these costs amount to about $\$ 6.5$ million per year. Total annualized capital and operating costs thus amount to almost $\$ 98$ million. 


\section{Costs for New Express Bus Service}

Estimates of express bus service costs are presented in Table 2. It is assumed that new express bus service would be introduced during peak periods, from 6 A.M. to 9 A.M. and from 4 P.M. to 7 P.M. (i.e., about six hours a day). It is estimated that this service would operate on the approximately 300 miles of limited-access highways in Washington, D.C. (i.e., about 600 route miles for both directions), at an average frequency of one bus every three minutes (i.e., an average of 20 buses an hour). It is assumed that each bus would travel an additional 20 percent of route miles off the freeway network to pick up and drop off passengers. Total revenue miles of service each day would be 86,400 route miles. Assuming an average bus speed (including intermediate stops for pick ups and drop offs) of $20 \mathrm{mph}$, total revenue hours of service per day would be 4,320 .

At an average bus speed of $20 \mathrm{mph}$, each bus would serve 120 revenue miles each day. Operating 86,400 revenue miles each day would require 720 buses. At a cost of about $\$ 340,000$ per bus (American Public Transit Association 2005), capital costs for buses would be $\$ 245$ million, or an annualized cost of about $\$ 35$ million assuming a 7 percent discount rate and 10-year bus life.

Based on cost data for Seattle, Washington (McDonald 2003), bus operating costs for a typical large metropolitan area may be estimated at $\$ 90$ per revenue hour. Due to the higher labor costs for split shifts and use of part-time labor for peakperiod service, costs for a typical express bus network are estimated to be from 1 to 10 percent higher than for conventional operations (Charles River Associates $2001)$, or a maximum of about $\$ 100$ per revenue hour. Operating costs would be $\$ 432,000$ per day or about $\$ 108$ million per year assuming weekday operations only (i.e., 250 days per year excluding holidays).

Total annualized costs for capital and operation of new express service are thus estimated at about $\$ 143$ million. This estimate does not include infrastructure costs for bus stops and shelters, bus storage, and maintenance facilities, etc. However, some cost savings would be realized with regard to operation of the existing transit system. Also, some existing transit infrastructure could be utilized for the new system.

Assuming a 10 percent reduction in peak-period vehicle trips due to pricing, a total of 0.4 million SOV trips would need to be shifted to either transit or HOV. Assuming that half of these trips are carried on transit, with the remaining shifting to carpools, about 0.2 million new transit person trips would need to be served. At an average transit passenger trip distance of 10 miles, 2 million passenger miles 


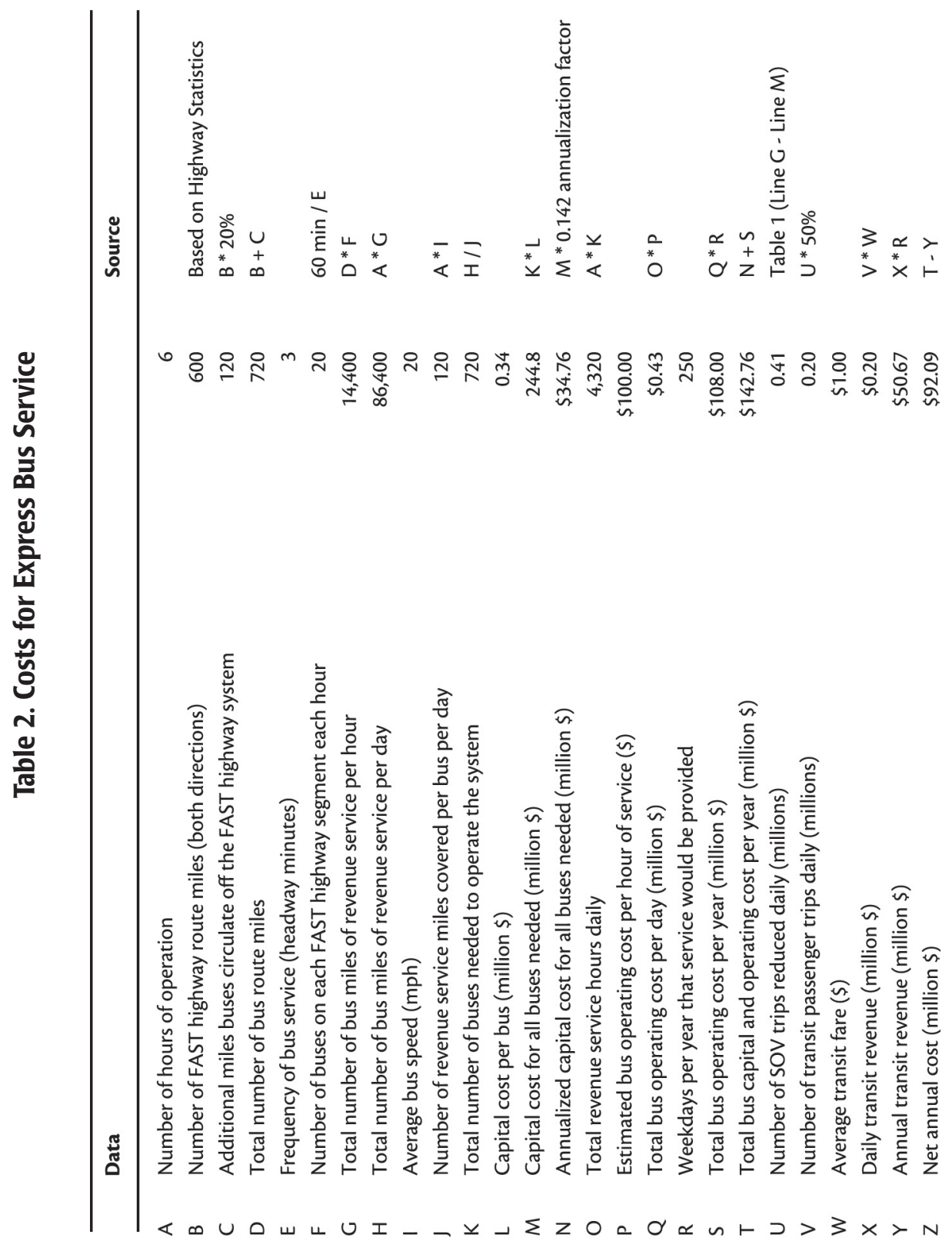


would be served. A shorter average transit trip length relative to auto trip length (i.e., 11.84 miles) was assumed to account for the additional driving distance for park-and-ride transit trips. On average, 23 passengers would be served per bus mile (i.e., 2 million passenger miles/86,400 revenue miles per day).

Revenues from transit passengers, conservatively assuming a fare of $\$ 1.00$ per trip, would amount to about $\$ 200,000$ per day, or about $\$ 50.6$ million per year for 250 days of service. Net annual transit agency costs per year would be about $\$ 93$ million.

\section{Financial Feasibility}

Table 3 presents estimates of potential toll revenue. As estimated above, FAST highways in Washington, D.C., would carry about 3.65 million peak-period highway trips, generating about 18 million vehicle miles per day. Assuming a set-aside of 3 million vehicle miles (i.e., about 17\%) for purchase by those who need extra miles, including nonresidents who would not be eligible for a free allocation, about 15 million miles would be traveled for free. Far more free miles could be offered to motorists, however, since many drivers will likely not use all their free miles during peak hours.

The average rate that solo drivers are charged during peak periods for use of the HOT lanes on $1-15$ in San Diego is about 25 cents per mile (i.e., about $\$ 2.00$ for the 8-mile trip) based on annual revenue of about $\$ 2.4$ million and an average of 5,000 paying solo driver trips on each of 250 weekdays (U.S. Department of Transportation 2004). Paying drivers are only a small fraction of the approximately 55,000 auto drivers who use $\mathrm{I}-15$ during the AM and PM peak periods each weekday (Supernak 2001). Like paying I-15 HOT lane users, many paying FAST highway motorists would be comparing travel times on alternate free routes with travel times on FAST highways in deciding whether to use FAST highways. However, they may be willing to pay higher toll rates for extra miles, because traveling an extra mile may allow them to avail of additional "free" travel time savings through use of their FAST Miles credits. For the purpose of revenue estimation, we may conservatively assume an average charge of 25 cents per mile (comparable to I15) for each of the 3 million extra miles available for purchase under a FAST Miles system. Thus, tolls paid for extra miles would bring in $\$ 750,000$ daily, or about $\$ 188$ million annually, over 250 weekdays. This amount is comparable to the total costs of about $\$ 191$ million estimated above for operating the FAST Miles program, 


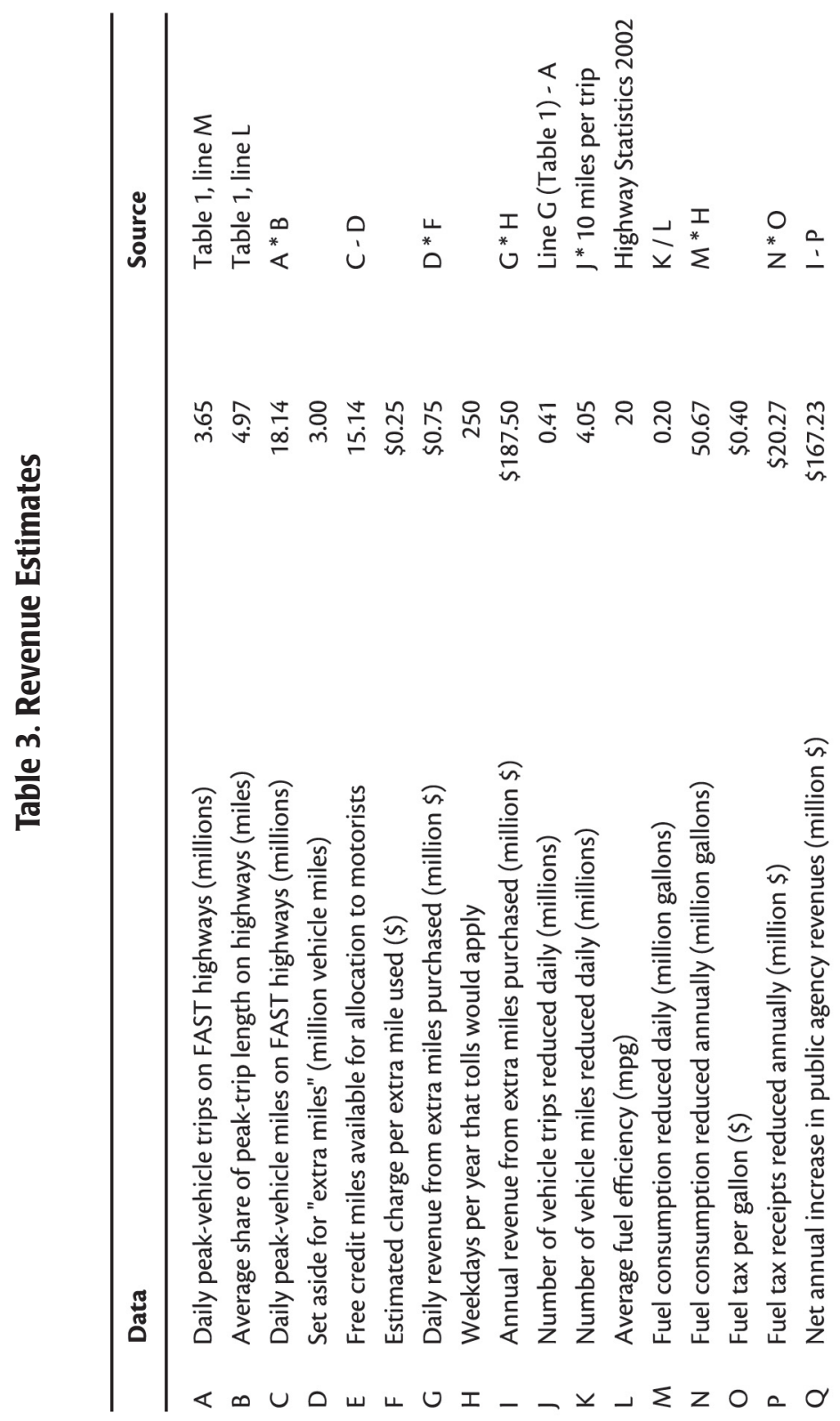


including costs for toll collection, credit distribution and traffic management (i.e., about $\$ 98$ million annually) and costs for new express bus service (i.e., about $\$ 93$ million annually).

However, there would be concomitant fuel tax revenue losses to state and Federal governments due to reductions in fuel consumption. This would result from the reduction in vehicle miles traveled as well as elimination of excess fuel consumption that previously resulted from stop-and-go traffic on the highways. At the current average state and Federal total fuel tax rate of about 40 cents per gallon and fuel efficiency of about 20 miles per gallon, these revenue losses are estimated at about $\$ 20$ million annually. This estimate assumes that the daily reduction of 0.4 million vehicle trips would result from a shift to carpools and transit with an average of 10 miles of the total previous SOV trip length of 11.84 miles carried on the carpool and transit portions of the commute trip. It also ignores reduced fuel consumption due to free-flowing traffic conditions.

\section{Benefits from FAST Miles}

With FAST Miles, the entire limited-access highway system would serve the purpose of a "fixed guideway" for transit. HOVs would get premium service free of charge on FAST highways when those participating in a carpool link together their FAST Miles accounts. Therefore, the need for tax dollars to support public investment in special express bus and HOV lanes would be eliminated, including costs for additional pavement and rights-of-way for new special-purpose bus/HOV lanes, for lane separation, for special ramps to provide access to and egress from the lanes, and for enforcement of vehicle occupancy requirements for carpools.

Maximum vehicle flow on limited-access highways occurs when highway speeds are 55 to $65 \mathrm{mph}$ (Chen and Varaiya 2002). Vehicle throughput on a severely congested freeway may be reduced significantly due to the increase in vehicle density and the concomitant drop in speeds. When traffic volumes reach a certain threshold level-approximately 2,000 vehicles per lane per hour or a vehicle density of about 35 vehicles per lane per mile-traffic flow breaks down, and speed as well as vehicle throughput decrease precipitously. This has been termed "the freeway congestion paradox" (Chen and Varaiya 2002). Even though demand may decrease after the peak period, the highway does not recover its full vehicle throughput capability until much later, because queued vehicles from previous hours keep vehicle density high and speeds slow. By ensuring that traffic flow does 
not break down in the first instance, FAST Miles may actually increase highway vehicle throughput in peak periods.

The variably tolled express lanes in the median of SR 91 in Orange County, California, demonstrate the ability of pricing to maximize highway throughput by keeping traffic at free-flow speeds. Speeds are 60 to $65 \mathrm{mph}$ on the priced express lanes. In the peak hour, they carry almost as many vehicles as do the congested free lanes even though there are twice as many free lanes (U.S. Department of Transportation 2004). Pricing the express lanes allows twice as many vehicles to be served per lane in the peak hour, at three to four times the speed on the free lanes. Almost half the public investment in SR 91's free lanes is simply wasted in peak hours. FAST Miles, however, can restore to full use the public investment that is being wasted every day in major metropolitan areas on congested highways, during critical times of the day when the investment is most needed.

A rough idea of the magnitude of travel time savings benefits to motorists on FAST highways may be obtained by a few simple calculations, as demonstrated in Table 4. When there are no incidents or accidents, typical speeds on highways in a large metropolitan area such as Washington, D.C., average 40 miles per hour in the peak periods (Safirova et al. 2003). FAST Miles would restore free-flow speeds averaging 60 miles per hour, except when collisions or incidents block traffic. Under normal conditions, this means that an average 5-mile limited-access highway trip would save a half-minute per mile, or 2.5 minutes over its entire trip length. Metropolitan areas are forecasted to experience increasing levels of congestion in the future. If average peak-period speeds were to drop to $30 \mathrm{mph}$ (from the current $40 \mathrm{mph}$ average), time savings to FAST highway motorists would double to 1 minute per mile driven, or 5 minutes over a 5-mile FAST highway trip.

The U.S. Department of Transportation (2002) estimates that an hour of travel time is valued at an average of about $\$ 12$ for all types of personal travel (or about $\$ 11.20$ in 2000 dollars). Thus, a single 5-mile highway trip would save about $\$ 0.50$ in travel time costs today based on 2.5 minutes saved, and as much as $\$ 1.00$ in the future based on 5 minutes saved. The 3.65 million FAST highway trips would save $\$ 1.8$ million to $\$ 3.6$ million per day, or almost $\$ 0.5$ billion to $\$ 1$ billion over 250 weekdays each year-not an insignificant benefit, and several times the estimated costs for implementing and operating FAST Miles.

Eliminating recurring congestion would also have additional benefits for express bus riders. The reliability of both transit and highway trip times would increase significantly. The value of travel time reliability has been estimated at 100 percent 


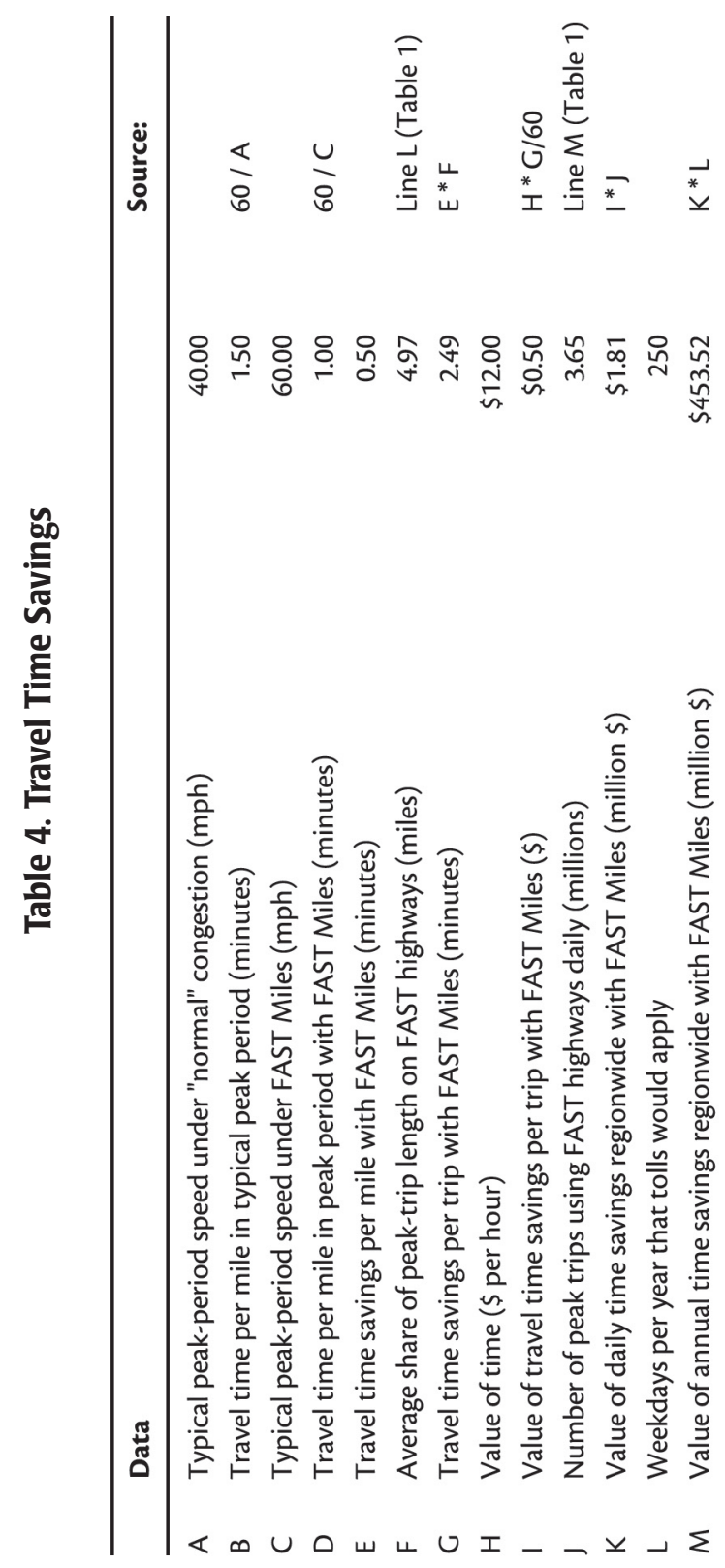


to 250 percent of the value of travel time savings (Brownstone and Small 2003; HLB Decision Economics Inc. and University of California at Irvine 2001). Eliminating recurring congestion will tend to reduce other delays, such as those caused by incidents, accidents, and road construction, since queues caused by such events will be shorter. Also, fuel consumption would be reduced. Thus, if benefits to transit riders, and additional benefits to motorists in the form of fuel savings, accident savings, and travel time reliability improvements are accounted for, total benefits to travelers on the FAST network would exceed by far the benefits estimated above based on motorist travel time savings alone.

Long-distance travelers who change their travel behavior in response to implementation of FAST Miles may suffer some disbenefits. Those travelers that respond by changing their travel route may also cause additional delays to other motorists on those routes. The key to ensuring that these disbenefits are minimized is to ensure that levels of service on alternative modes (mainly transit and HOV) are enhanced as much as possible so that the aggregate "disutility" of cost, travel time, and inconvenience of these modes (including access and egress) is no higher than the aggregate disutility of cost, travel time, and inconvenience of driving alone on congested highways prior to establishment of FAST Miles.

Disbenefits may also accrue to those priced off the FAST highways and those using parallel alternative routes in the vicinity of FAST highways, due to added delays that may result from diversions to these routes. However, negative impacts from traffic diversion can be minimized through use of surplus FAST Miles revenue for investments in advanced arterial signal systems. This will help accommodate traffic diversions, if any. Due to increased vehicle throughput on free-flowing freeways, however, diversions from arterials to FAST highways may exceed any diversions from FAST highways to arterials. Empirical evidence from SR 91, as discussed earlier, suggests that the higher throughput on the two priced lanes (per direction) allows more traffic to be carried through the corridor than would have been possible if all six lanes (per direction) were free. Since FAST highways are expected to carry more vehicles than they did under congested conditions, the burden of traffic on parallel arterials may actually be reduced.

As travel demand increases in the future, extra mile charge rates will also rise, providing more FAST Miles revenue-and making appropriate investments in highway expansion and transit and HOV services, including access to and egress from transfer locations, more financially feasible. 
By reducing vehicular travel, FAST Miles would lead to lower automobile pollutant emissions and improve metropolitan air quality. Urban sprawl may be discouraged if people choose to live closer to their jobs in order to reduce FAST Miles charges, rather than choosing to live far from urban centers to take advantage of free highways and lower housing prices, as many do now.

On the other hand, the choice to live further away from dense urban centers may become more appealing to some as a result of the provision of new express bus services and ancillary access and egress improvements, new opportunities to form carpools, an increase in FAST highway vehicle throughput due to elimination of high levels of recurring congestion, and improved levels of highway service due to elimination of traffic flow breakdowns. Creation of new transportation capacity, whether through new transit and HOV investments or through elimination of inefficiencies on the existing highway system, does have the potential to induce new development further away from city centers.

To reduce this effect, it will be important for government agencies to forewarn those choosing to live far from urban centers that FAST Miles charges for extra miles may increase in future, especially if new transportation capacity does not keep pace with growth in peak-period vehicular travel demand. This is exactly the situation currently being experienced with regard to toll rates on the SR 91 express lanes in Orange County. The facility serves commuters from the rapidly growing suburban community of Riverside County, and maximum toll rates for the 10-mile segment have increased from about $\$ 2.5010$ years ago to almost $\$ 8.00$ today due to rapid growth in travel demand in the corridor.

\section{Public Acceptance}

How will the public react to FAST Miles charges? Table 5 presents the major public acceptance issues associated with road pricing and how FAST Miles attempts to address them.

The public appears to have little confidence in the effectiveness of adjustable tolling as a traffic reduction strategy. The Washington Post-ABC News poll cited earlier (Langer 2005) found that only 7 percent of people believe that such tolling is very effective as a traffic remedy. However, carpooling and transit are believed to be very effective by 39 percent and 42 percent of people, respectively. Since FAST Miles is an integrated multimodal strategy that would include significant incentives for carpooling and transit, the public may have greater confidence in 
Table 5. Public Concerns

\begin{tabular}{|l|l|}
\hline \multicolumn{1}{|c|}{ Public Concern with Road Pricing } & \multicolumn{1}{c|}{ How FAST Miles Addresses the Concern } \\
\hline $\begin{array}{l}\text { Public does not believe adjustable tolls are } \\
\text { effective }\end{array}$ & $\begin{array}{l}\text { Adjustable tolls are combined with transit and } \\
\text { HOV improvements that have high public support }\end{array}$ \\
\hline Public opposes "new" charges for road use & $\begin{array}{l}\text { Tolls apply only to those who use more than their } \\
\text { fair share of peak highway capacity, and tolls are } \\
\text { only charged if the payer gets congestion-free service }\end{array}$ \\
\hline $\begin{array}{l}\text { Public is concerned about government } \\
\text { knowing where and when they travel }\end{array}$ & $\begin{array}{l}\text { Private operator operates tolling, and deletes all } \\
\text { travel data at day's end }\end{array}$ \\
\hline $\begin{array}{l}\text { Public is concerned about equity for low } \\
\text { income motorists }\end{array}$ & $\begin{array}{l}\text { All motorists get an equal share of free credit } \\
\text { miles; only motorist who use the freeways heavily } \\
\text { during peak periods would have to pay more }\end{array}$ \\
\hline $\begin{array}{l}\text { Neighbors are concerned about diversion of } \\
\text { traffic to free roads }\end{array}$ & $\begin{array}{l}\text { New transit and HOV options will reduce total } \\
\text { traffic, and FAST highways will carry more traffic, } \\
\text { reducing the traffic burden on parallel arterials }\end{array}$ \\
\hline
\end{tabular}

the effectiveness of FAST Miles. While only 29 percent of those surveyed favor adjustable tolls, 51 percent support HOV lanes (Langer 2005). With FAST Miles, the entire highway system would, in effect, be transformed into an HOV system that provides premium service for HOVs, express buses, and paratransit services. Therefore, the FAST Miles concept may get a higher level of support from the public than adjustable mileage charges by themselves would.

However, some people may still oppose the "new" charges, especially those who currently drive alone for long distances. Their concerns may be alleviated somewhat by guaranteeing that no charges will be made to their FAST Miles accounts for any miles for which they did not get congestion-free service.

Some may be concerned about the new ability of the government to monitor their vehicle movements. These public concerns may be alleviated if a private operator is hired to run the system and the government does not control the data, as in the case of credit card companies. Additionally, the private operator could be required to discard all data daily at the end of the afternoon peak period, saving only the gross amount of money charges incurred by each account holder on that day. Motorists may request that their daily usage data be forwarded to them electronically at the end of each day before being erased from the system, so they could check for accuracy of charges.

Will elected officials and the public perceive FAST Miles as equitable? Road pricing schemes that have been implemented to date tend to require motorists to 
bear new charges if they want to avail themselves of premium highway service. Consequently, premium-service facilities, such as the SR 91 express lanes in Orange County, California, have disproportionately higher use by high-income motorists (U.S. Department of Transportation 2004). On the other hand, with FAST Miles most highway travelers would be guaranteed a reliable and congestion-free trip for free, with all motorists allocated an equal number of free miles regardless of income level. If a trading system were put in place to permit buying and selling of FAST Miles credits, low-income motorists, who tend to drive fewer miles, could cash in on their unused miles. If some revenues were dedicated to subsidizing bus service, which is used more often by low-income travelers, this would also enhance equity.

With FAST Miles, those who have long commute trips and choose to continue to drive solo would, through charges for extra miles, pay for highway capacity expansion to accommodate their more intense usage, or to accommodate some travel demand on transit and in carpools, including costs for access and egress improvements at transit stations and carpool park-and-ride facilities. Shifts in mode of travel encouraged by these improvements would free up existing highway capacity to accommodate the remaining long vehicle trips more efficiently. The rest of the public would not have to pay for disproportionately higher demands placed on the highway system in peak periods by a few trip-makers - either through congestion delays imposed upon them, as under the existing system; or through new taxes or tolls that are often proposed to pay for new capacity to relieve that congestion. Opposition to new charges based on the perception of "double taxation" would be weakened. Every motorist would get a share of peak-period use of FAST highway facilities "already paid for" through his or her taxes. Those who would like to avail of greater use would have a choice to do so by paying for it.

Won't commuters with longer trips simply divert to free roadways and cause additional congestion on them, infuriating local residents? The public is well aware that when tolls are raised on existing tollways, some drivers divert to free alternatives. However, FAST Miles does not simply involve new charges; a package of reasonably convenient transit and HOV options is included to make simple diversion to free roadways less appealing to the solo driver. Research by Washbrook (2002) suggests that, while improvements in travel time for carpools and transit by themselves do not generally achieve a high level of mode shift, these improvements can be extremely effective when combined with an increase in charges for road use or parking. When new highway charges are combined with carpooling and transit 
improvements, traffic may actually be reduced on parallel arterials because some arterial travelers who were previously deterred by freeway congestion may shift back to free-flowing FAST highways whose vehicle throughput has increased (as on the SR 91 express lanes), at the same time that corridor vehicular demand is reduced due to increased use of alternative modes.

\section{Public-Private Partnership Possibilities}

A new model for partnerships with the private sector could be used to implement and operate FAST Miles and supporting transit and carpool systems. Private operators of FAST highways could be paid by public agencies based on the number of free-flowing vehicle miles of travel provided in peak periods, with appropriate reductions in fees for those vehicle miles that are not congestion-free (DeCorlaSouza and Barker 2005). For example, the private partner may be paid for a vehicle trip carried at $45 \mathrm{mph}$ on the facility at three quarters of the rate that would apply if the trip were carried at $60 \mathrm{mph}$. Operators would thus have an incentive to ensure that the entire pricing scheme is set up to optimize vehicle throughput on the highway system at the highest speeds.

All revenues from extra mileage charges would go to public agencies. Thus, private operators would have no incentive to keep extra mile rates higher than they need to be for the purpose of managing demand, and would instead have an incentive to keep the rates as low as possible to maximize use without degrading levels of service. Potential private operators could be selected based on open competition. Criteria for selection could include the lowest fee per free-flowing vehicle mile they would be willing to accept as compensation for their services.

Technologies to count vehicle occupants (such as through heat sensing) are currently in the experimental stage. In the future, as such technologies come to market, it may be possible to enter into more comprehensive agreements with private sector toll and transit operations consortiums to manage the entire multimodal transportation system. The consortium would be paid for performance with respect to the metropolitan community's goal of maximizing mobility and access. Fees would be based on the number of persons carried on FAST highways and their speed of travel during peak periods. This would provide an incentive to the private sector to make the most cost-efficient modal investments and to promote and encourage ridesharing and transit use. An example of such a private operation, with a public sector role in planning, regulation, and monitoring, may be seen in 
Rome, Italy. The city's public transport and private automobile mobility services have been combined into a single private company called ATAC (translated in English as Agency for Bus and Rail Transport in the Municipality of Rome). Private automobile mobility services provided by this company include normal highwayrelated Intelligent Transportation System services as well as the operation of the downtown access control system, which charges fees for private vehicle entry into Rome's historic district to control congestion and air pollution.

To encourage increased private provision of new transit services, private operators of transit services could be made eligible for subsidies based on FAST Mile credits turned in by their patrons. For example, assuming a market value of 25 cents per credit mile, if a patron turned in 10 free miles per day from his or her FAST Miles account, the transit operator would be eligible for a total public payment of $\$ 2.50$ per day (i.e., \$1.25 per one-way trip). Private entrepreneurs would thus have incentives to establish targeted paratransit or vanpool services to cater to the needs of long-distance commuters. These incentives may be particularly appropriate in markets where existing public transportation is inadequate.

Private provision of services for access and egress at transit stations and carpool transfer locations may be encouraged by allowing the use of FAST Miles credits as payment for service, with reimbursements provided by the public sector. Private businesses may be encouraged to establish and operate bike rental services, shuttle bus services, and shared-ride taxi services at transit transfer locations, if FAST Miles credits can be used by their customers to pay for their services.

\section{Phasing In FAST Miles}

It is important that an enhanced transit system be in place before the FAST Miles credit/charging program goes into operation. Introducing monetary prices for rush-hour use of highways by itself will have a very limited impact if transit travel options are not already available and well understood by the traveling public. This may present a "chicken-and-egg" problem with regard to funding, since transit investments will need to be made and services will need to be established before revenues from FAST Miles operation begin to kick in. Thus, it will be important to secure in advance the public funding needed. A possible source might be the issuance of bonds backed by the future stream of revenues after FAST Miles implementation. 
However, the critical time advantages needed for success of transit services are difficult to provide before free-flowing traffic conditions are created by FAST Miles. Creative ways to develop travel time advantages for transit may be needed. One potential solution is to establish an extra transit lane on proposed FAST highways by restriping the highway to allow shoulder use as a transit lane, during rush hours. For example, a "rush-hour lane" has been implemented on I-66 outside Washington, D.C.'s Beltway, and such rush-hour lanes are more extensively used in the Netherlands.

With bus lanes and express bus services in place in advance of FAST Miles implementation, commuters will have an opportunity to understand and experience some of the travel time advantages that a full-fledged FAST Miles system might provide after the entire highway is free-flowing. To increase public understanding of the new and enhanced transit system, it will be important to implement complementary travel demand management programs, such as:

- Free transit trial periods (as in Seattle, Washington)

- Web-based pre-trip planning programs (as in the Netherlands) that allow commuters to compare the door-to-door travel times and costs of alternative modal combinations, as well as alternative start times for their commute trips

- Individualized marketing programs (such as in Lund, Sweden), where commuters are visited in their homes or at their job sites by transportation advisors who discuss the various travel options available to them

\section{Concluding Thoughts}

FAST Miles attempts to use free market principles on highway systems to encourage transit and HOV use and to eliminate recurring highway congestion. There appears to be sufficient discretionary use of solo driving on the highway system to induce significant changes in motorists' travel choices. This could reduce vehicle demand below the volumes at which highway traffic flow breaks down. While implementation and operating costs could be significant, benefits in a large metropolitan area could exceed public costs for operating FAST Miles by several orders of magnitude. Also, FAST Miles could be self-financing. It could introduce new possibilities for public-private partnerships for the efficient and effective provision of transportation services, including highway and bus operations, and passenger collection and distribution services. 
New road user charges would be packaged with incentives for transit and carpool use, which have higher levels of public support than road pricing by itself. FAST Miles would provide an equal amount of premium service free of charge to motorists of all income levels and impose new charges for use of existing highways on only those who choose to use highways far more than others during peak times when highway space is scarce. However, concerted efforts will need to be made to involve the public in the detailed development of the concept to alleviate their concerns. FAST Miles and its benefits are complex and difficult to explain in a sound byte.

Metropolitan Planning Organizations may be best positioned to conduct the type of extensive public involvement needed to alleviate the public's concerns and to develop more detailed concepts with public participation. A pilot demonstration of the concept may be needed to convince the public of its merits. Implementing FAST Miles will be no easy task. The highly successful congestion-charging scheme established in central London in 2003 is smaller in scale than a regionwide application of FAST Miles would be. Yet it took many years of preparation, bold political leadership, and a favorable institutional setting to establish the central London scheme.

\section{Acknowledgments}

The author would like to acknowledge helpful comments on the FAST Miles concept from Jeffrey Lindley, Eric Gabler, and Bruce Spear of the Federal Highway Administration (FHWA) and several colleagues at the Office of the Secretary (OST) of the U.S. Department of Transportation. However, the author alone is responsible for any errors or omissions, and the views expressed are those of the author alone and not necessarily those of the U.S. Department of Transportation or the FHWA. 


\section{References}

American Public Transit Association web page accessed August 29, 2005 at: http:// www.apta.com/research/stats/bus/buscost.cfm.

Berg, J. T., K. Kawada, M. Burris, C. Swenson, L. Smith, and E. Sullivan. 1999. Value pricing pilot program. TR News 204: 3-10. Transportation Research Board.

Brownstone, David, and Kenneth A. Small. 2003. Valuing time and reliability: Assessing the evidence from road pricing demonstrations. Forthcoming in Transportation Research Part A. Available on web (accessed May 6, 2004) at: http://www.socsci.uci.edu/ ksmall/VOT-VOR-AEA11.pdf.

Cambridge Systematics, Inc. and URS Corporation. 2005. MnPass system study. Final Report. Prepared for the Minnesota Department of Transportation.

Charles River Associates, Inc. 2001. Part time operators: The trends and impacts. TCRP Report 58, TRB, NRC, National Academy Press, Washington DC.

Chen, Chao, and Pravin Varaiya. 2002. The freeway-congestion paradox. Access (20).

DeCorla-Souza, Patrick. 1994. Applying the cashing out approach to congestion pricing. Transportation Research Record 1450: 34-37. Transportation Research Board.

DeCorla-Souza, Patrick. 2005. FAIR highway networks: A new approach to eliminate congestion on metropolitan freeways. Public Works Management \& Policy 9 (3): 196-205. SAGE Publications.

DeCorla-Souza, Patrick, and William G. Barker. 2005. Innovative public-private partnership models for road pricing/ BRT initiatives. Journal of Public Transportation 8 (1). Center for Urban Transportation Research.

HLB Decision Economics Inc. and University of California at Irvine. 2001. The value of reliability in congested conditions. National Cooperative Highway Research Program Report 431. Transportation Research Board.

ITS Decision, Service and Technologies. 2005. Web site accessed May 6, 2005: http://www.calccit.org/itsdecision/serv_and_tech/Electronic_toll_collection/ electron_toll_collection_report.html. 
Langer, Gary. 2005. ABC news poll: Traffic in the United States: A look under the hood of a nation on wheels. ABC News, February 14. Available at: http://abcnews.go.com/Technology/.

McDonald, Douglas B. 2003. Measures, markets and mileposts. The Gray Notebook for the Quarter Ending March 31, 2003: 33. Washington State Department of Transportation.

Safirova, E., K. Gillingham, I. Perry, P. Nelson, W. Harrington, and D. Mason. 2003. Welfare and distributional effects of road pricing schemes for Metropolitan Washington, DC. Discussion Paper 03-57. Resources for the Future. Washington, DC.

Schrank, David, and Timothy Lomax. 2005. The 2005 urban mobility report. Texas Transportation Institute. Available at: http://mobility.tamu.edu/ums/report/.

Supernak, Janus. 2001. I-15 Congestion Pricing Project Monitoring and Evaluation Service, Task1: Phase II Year Three Traffic Study. Prepared for the San Diego Associations of Governments.

Transportation Research Board. 2000. Highway capacity manual.

U.S. Department of Transportation and Federal Highway Administration.1999. Summary of travel trends: 1995 Nationwide personal transportation survey.

U.S. Department of Transportation. 2002. Memorandum on revised departmental guidance for valuation of travel time in economic analysis. Washington, DC. 2002. Available at: http://ostpxweb.dot.gov/policy/safety/VOT_Guidance_ Revision_1.pdf.

U.S. Department of Transportation. 2003. Highway statistics 2002. Table HM-71: $\mathrm{V}$-43. Washington, DC.

U.S. Department of Transportation. 2004. National household travel survey 2001. Available at: http://nhts.ornl.gov/2001.

U.S. Department of Transportation. 2004. Report on the value pricing pilot program through March 2004. Available at: http://knowledge.fhwa.dot.gov/cops/hcx. nsf/All+Documents/AD276ECC2E3A077885257005006B5614/\$FILE/March\%20 2004\%20Report\%20of\%20Congress.pdf.

Wachs, Martin. 2003. Congestion in cities-Where, when, what kind, how much. Traffic Congestion: Issues and Options. Presentation at the Conference held in Washington DC, June 26-27. UCLA Extension Public Policy Program. 
Washbrook, Kevin. 2002. Assessing the potential of road and parking charges to reduce demand for single occupancy vehicle commuting in the Greater Vancouver region. Research Project No. 298. School of Resource and Environmental Management, Simon Fraser University.

Washington Post. 2005. Riding Metro. March 6.

\section{About the Author}

Patrick DeCorla-Souza (Patrick.DeCorla-Souza@fhwa.dot.gov) is team leader for Highway Pricing and System Analysis in the Office of Transportation Policy Studies at the Federal Highway Administration (FHWA) in Washington, D.C. He manages FHWA's Value Pricing Pilot Program. In this capacity, he works with public and private sector partners in 15 states to implement innovative road-pricing strategies. He has published extensively on topics relating to road pricing, air quality, travel demand modeling, land use strategies, benefit-cost analysis, and cross-modal evaluation. Mr. DeCorla-Souza chairs the Transportation Research Board's Joint Subcommittee on Road Pricing. 